\section{Clinical and Academic Anaesthetists Required}

The Department of Anaesthesia invites applications for positions at the London Health Sciences Centre and St. Joseph's Health Centre, London, Ontario.

We are seeking individuals with appropriate skills in a wide variety of areas including neuro, cardiac, vascular, thoracic, transplantation, paediatric and obstetric anaesthesia, as well as critical care, pain management, pharmacology, informatics, clinical trials or education.

London Health Sciences Centre is a 990 bed tertiary care centre created by the merger of University and Victoria Hospitals and is the main teaching hospital for the University of Western Ontario. St. Joseph's Health Centre is affiliated with the University of Western Ontario and is the tertiary obstetric centre. The Departments have a very busy clinical service as well as active research and teaching programs.

Academic rank and competitive contractual arrangements will be commensurate with experience and qualifications. Candidates must be FRCPC certified or equivalent and be eligible for licensure in Ontario. In accordance with Canadian Immigration requirements, this advertisement is directed to Canadian citizens and Permanent Residents of Canada. The University of Western Ontario is committed to employment equity, welcomes diversity in the workplace and encourages applications from all qualified individuals including women, members of visible minorities, aboriginal persons and persons with disabilities. Positions are subject to budget approval.

Please send applications with curriculum vitae and the names of three referees to:

Dr Adrian W. Gelb, Professor and Chair, Department of Anaesthesia, London Health Sciences Centre,

339 Windermere Rd, London, Ontario, Canada N6A 5A5

Ph: 519.663-3270

Fax: 519-663-3079

E-mail: agelb@julian.uwo.ca

\section{- \\ Department of Anaesthesia \\ The Montreal General Hospital}

The Montreal General Hospital, has a full time position available for a specialist Anaesthetist, who has post graduate fellowship training in transoesophageal echocardiography. The Montreal General Hospital is a McGill University teaching hospital and referral centre for adult tertiary care including trauma.

Over 500 open heart surgeries are performed annually in an expanding programme.

The successful applicant will be in charge of transoesophageal echocardiography using state of the art equipment and he/she will be expected to develop a teaching programme for staff and residents.

Intended applicants must:

1. Hold or be eligible for licensure in the specialty of Anaesthesia with the Collège des Médecins du Québec.

2. Have Royal Canadian College certification in Anaesthesia.

3. Have a working knowledge of French.

Applicants should provide an up-to-date Curriculum Vitae and the names of three referees.

In accordance with Canadian Immigration requirements, this advertisement is directed towards Canadian citizens and permanent residents.

Applications should be addressed to:

Dr. Ian R. Metcalf, Anaesthetist-in-Chief

The Montreal General Hospital

1650 Cedar Avenue, Room D6-245

Montreal, Quebec H3G 1A4

TEL: (514) 937-6011 ext. 3030 FAX: (514) 934-8249 7th Annual

Whistler Winter Anaesthesia Refresher Course \& Review

February 28 - March 6, 1998

Whistler, British Columbia, Canada

21 hours CME credits poster presentations

For information:

Whistler Winter Anaesthesia Meeting

Department of Anaesthesia Kingston General Hospital

76 Stuart Street

Kingston, Ontario, Canada, K7L 2V7

Voice Mail: (613) 544-3400 Ext. 3215

Fax: (613) 548-1375

E-mail: depanes@post.queensu.ca
Winterlude'98 Anaesthesia Symposium - University of Ottawa

\section{Clinical Perspectives:}

\section{The Practice and the Practical}

Chateau Laurier Hotel

Saturday, February 21, 1998

Moming Session:

Fulminant Liver Failure - Dr. L Torsher - Rochester, MN

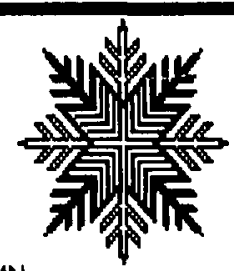

Autologous Blood in High-Risk Patients - Dr. J. Cormack - Edmonton, AB Spinal Anaesthesla in NICU Bables - Dr. W. Taylor - Windsor, ON TE Echocardiography in OR and ICU - Dr. C. Tousignant - Toronto, ON Acupuncture and Chronic Pain - Dr. K. Monteith - Moncton, NB Paediatric Anaesthesia - Teaching from Near and Afar

$$
\text { - Dr. J. Henderson - Montreal, PQ }
$$

Aftemoon Smal/-Group Sessions:

(Choose any 3 of these 6 Toplcs - Each session 3-4 Cinica/ Scenarios for Discussion) Topic A: Blood and Anaesthesia - Drs. J. Cormack and E. Crosby

Topic B: Anaesthesla and the ICU - Drs. C. Tousignant and J. Hooper

Topic C: The Trauma Victim - Drs. W. Taylor and I. Zunder

Topic D: Paediatric Potpourri - Drs. J. Henderson and C. Reld

Topic E: Pre-Admit Assessment - Drs. L. Torsher and J. Kitts

Topic F: Chronic Pain Management - Drs. K. Monteith and J. Watson

Speciall $U$ of $O$ Alumni Reunion Reception to follow Symposium.

$\begin{aligned} \text { For Information } & \begin{array}{l}\text { Ms. Lynne MdHardy, Secretary } \\ \text { Winterlude '98 Symposium } \\ \text { Dept Anaesthesia, University of Ottawa } \\ \text { Ottawa Clvic Hospital - 83 }\end{array} \\ \text { Wordd Wide Web } & \begin{array}{l}1053 \text { Carling Ave, Ottawa ON K1Y 4E9 } \\ \text { phone: (613) 761-4940 } \\ \text { email: Imchandy) civichortawa onca }\end{array}\end{aligned}$

Winterlude '98 Anaesthesia Symposium - University of Ottawa 